\title{
A Comparative Study of Three Widespread Methods for Extracting Plant-Parasitic Nematodes from Soil Samples
}

\author{
El -Marzoky A. M. \\ Plant Prot. Dept., Fac. Agric., Zagazig University, Egypt \\ E-mail: amr_elmarzoki@yahoo.com
}

\begin{abstract}
This study was conducted in a productive farm characterized by heterogeneous soil type and planted with Balaika bananas (Musa maghrabi) in Al-Sharkia Governorate, Egypt. Three soil types namely sandy, sandy clay, and clayey soil were determined in this farm. Three methods were selected for extracting plant-parasitic nematodes present in the previous soil types. These methods were extraction trays (ET), decanting plus sieving (DS) and centrifugal flotation (CF) methods. Results showed that the centrifugal flotation was the most efficient extraction method. The relative efficacy of the extraction (\%) in the DS method was 36.76 and $39.29 \%$ in sandy clay and clayey soil, respectively while, in the CF method it was $35.94 \%$ in clayey soil type, for genus Meloidogyne. The inactive nematode genera e.g. Criconemoides was not extracted by ET and DS methods in sandy and sandy clay soil types. The most efficient method for extracting this genus was the CF method it recorded 51.82 and $47.77 \%$ in sandy and clayey soil types, respectively. In this comparative study it could be concluded that the centrifugal flotation method $(\mathrm{CF})$ was the most efficient method for extraction the sluggish and motile nematodes, take short time for extraction, and the final suspension was clear. On the other hand, the ET method using a small amount of water had an importance today in water management strategy.
\end{abstract}

Keywords: Balaika bananas, extraction trays (ET) method, decanting plus sieving

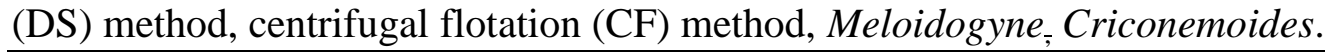

\section{INTRODUCTION}

Sampling and extraction are the first important steps for ecological and diagnostic studies. The major objective of the extraction method is to get a clear suspension for examination and identification. There are many extraction methods for nematodes from soil samples, which depend on many factors such as nematode species, mobility, soil type, the purpose of the extraction, specific gravity, and cost- benefits (Van Bezooijen, 2006).

Many authors discussed the extraction methods from soil samples over the past decades e.g. Oostenbrink (1960); Seinhorst (1988); Hooper et al. (2005) and Van Bezooijen (2006). Among these methods sieving plus extracting trays, decanting plus sieving and centrifugal flotation. These methods are simple, not expensive, not take a 
lot of time and don't use a lot of water (McSorley 1987). For these reasons this comparative study was designed to determine the efficacy of the previous methods.

Plant-parasitic nematode genera e.g. Meloidogyne, Helicotylenchus, Tylenchorhynchus, Criconemoides, and Pratylenchus are mainly infecting many of economic crops. These genera varied in size, weight, shape, parasitism, and mobility. There is no specific method for extracting each of these nematode genera. The extraction principle of these methods depends on the specific gravity and nematode mobility when using sieving plus Baermann method or on specific gravity and nematode weight in the case of decanting plus sieving method while, centrifugal flotation method principle depends on centrifuging force and nematode flotation (Anon, 2013).

This study focuses on the efficacy of the three previous extraction methods for extracting plant-parasitic nematodes from soil samples with referring to the role of soil composition in the extraction and the advantages and disadvantages of each method.

\section{MATERIALS AND METHODS}

\section{Collecting soil samples:}

This study was conducted in a farm cultivated with Balaika bananas (Musa maghrabi) and infested with different species of plant-parasitic nematodes. This farm, about ten feddans of heterogeneous soil types, was located at El-Moulak valley, ElSharkia Governorate, Egypt. Initial soil samples were collected from the determined localities in the farm and sent to the Research Laboratory Center, Faculty of Agriculture, Zagazig University for mechanical soil analysis. Three soil types in the experimental farm were determined as the following: sandy, sandy clay, and clayey soil. The mechanical differences between the three soil types are shown in Table (1).

About five kilograms of the soil rhizosphere were collected from each soil type, each sample consisted of ten subsamples collected randomly from the determined localities. Samples were put in a plastic bags and send to the laboratory in Faculty of Agriculture, Zagazig University, for extraction, the samples were left in the refrigerator at $9{ }^{\circ} \mathrm{C}$ the second day and extracted.

Table 1. Mechanical analysis of soil samples used in extraction methods comparison.

\begin{tabular}{|l|c|c|c|c|}
\hline Sample series & \% Clay & \% Silt & \% sand & Soil type \\
\hline Type 1 & 6 & 7 & 87 & Sandy \\
\hline Type 2 & 42 & 4 & 54 & Sandy clay \\
\hline Type 3 & 55 & 14 & 31 & Clayey \\
\hline
\end{tabular}




\section{Nematode Extraction Methods:}

In this study, three simple widespread and non-expensive extracting methods were used. The soil samples used in the extraction methods were different in size from method to another, for that and all soil samples were finally imputed to $250 \mathrm{~g}$.

\subsection{Extraction Trays Method (ET):}

This method is a modification of the Baermann technique which was described the first time by Whitehead and Hemming (1965). A wide mesh plastic tray was covered its bottom and sides with a single sheet of tissue paper and put into another plastic tray. About $50 \mathrm{~g}$ of the collected soil samples were placed in tissue paper and spread in a thin and uniform layer and then gently poured tap water over the soil and this was repeated for each soil type.

After 24 hours the suspension collected in the plastic tray was poured over a fine sieve (400 mesh sieve) for concentrating and then the suspension was ready for examination. The final suspension was clear and the nematodes were active.

\subsection{Decanting plus Sieving Method (DS):}

This method was firstly described by Cobb (1918), and modified by S'Jacob \& Van Bezooijen (1984); Southey (1986), to extract active nematodes from soil. About $300 \mathrm{~g}$ of each soil type sample was divided into three equal samples as replicates, each $100 \mathrm{~g}$ of the soil sample was stirred with water-filled $250 \mathrm{ml}$ beaker to separate nematodes from soil particles. After 15 seconds the heavy particles were stilled, and then the supernatant suspension was poured off in two sieves (275 and 400 mesh). The nematode suspension on the 400 -mesh sieve, was collected in $15 \mathrm{ml}$ bottle for examination. Depending on the specific gravity, variation between the nematode and the soil particles, the nematodes were floated up in the suspension and then a tissue paper was used for clearing the suspension. This method does not consume a lot of tap water and so it can be used out of the laboratory, do not take time for extraction compared for the other methods and the extracted nematodes were very active and can use in inoculation studies.

\subsection{Centrifugal Flotation Method (CF):}

The first who described this method was Gooris and D'Herde (1972). In this method the nematode extraction depends on the effect of centrifugation force to separate the nematode from the other sediments and the specific gravity of the extraction fluid compared to nematodes and other particles in the suspension. If the sample is suspended in extraction fluid with a higher specific gravity compared to nematodes, so that the nematodes-float, on the other hand, the particles with a higher specific gravity compared to the extraction fluid, submerge.

About $250 \mathrm{~g}$ of the soil samples were soaked in $4 \mathrm{~L}$ washing dish for about two minutes, mixed well with the water, and left until the heavy soil particles were deposited down. The washing supernatant was poured over two sieves (275 and 400 mesh) and all the sieves contents were transferred gently with tap water to $100 \mathrm{ml}$ beaker for extraction by the centrifuge.

The extraction fluid was made by added $450 \mathrm{~g}$ of sugar to 1 liter of the distilled water. The nematode suspension was transferred to centrifuge tubes and centrifuged it 
for 7 minutes at $1750 \mathrm{rpm}$, the supernatant was decanted and throw away from the tubes and then the sugar solution was added to the tubes and centrifuged for 3 minutes at the same rpm, the final suspension was poured over 400 mesh sieve and rinsed with the tap water for wash the sugar solution residues, all the sieve contents were transferred for examination. This method was not expensive, take no time for nematodes extraction and the examined suspension was clear and suitable for all nematodes active and inactive species. However, the nematodes extracted by this method were not alive and cannot use in inoculation experiments.

\section{Statistical analysis:}

After extraction, the numbers of the nematode individuals for each genus was counted and the Relatively Efficacy of Extraction (REE\%) was calculated for each method by this equation:

$$
\mathrm{REE} \%=\frac{\text { No.of nematode individuals extracted by the method }}{\text { Total number of the nematodes extracted by the three methods }} \times 100
$$

Moreover, means of the replicates were compared by Duncan's multiple range test at $(\mathrm{P} \leq 0.05)$ with a software program (MSTAT,1987).

\section{RESULTS AND DISCUSSION}

Five genera of plant-parasitic nematodes had occurred all over the samples. Those genera were Meloidogyne, Helicotylenchus, Tylenchorhynchus, Criconemoides and Pratylenchus. All genera were morphologically identified after extraction by the three previous methods. Data in the Table (2) showed the effect of sandy soil (type 1) on nematode numbers extracted by the three tested methods. There are significant differences between the ET method and the two other methods. The nematode numbers were lowest in the ET method which were 268.33, 38.33, 40,00 and 10.66 individuals in $250 \mathrm{~g}$ soil for the genera Meloidogyne, Helicotylenchus, Tylenchorhynchus, Criconemoides and Pratylenchus, respectively. On the other hand, there is no significance between the DS and CF methods. The ring nematode, Criconemoides recorded 22.00 and 23.66 individuals in $250 \mathrm{~g}$ soil for DS and CF methods, respectively this result may be due to inactivity of the nematode species.

Data in Table (3) illustrated the effect of sandy clay soil (type 2) on nematode population extracted by three methods. There is no signification between the DS and CF methods for Meloidogyne which recorded 473.33 and 476.00 juveniles per $250 \mathrm{~g}$ soil, respectively. On the other side, it recorded 375.00 juveniles per $250 \mathrm{~g}$ soil in the ET method. The largest numbers of the nematodes extracted were in CF method which recorded 154.66, 98.00, 64.00 and 66.00 individuals per $250 \mathrm{~g}$ soil for genera Helicotylenchus, Tylenchorhynchus, Criconemoides and Pratylenchus, respectively, while the lowest numbers were recorded in the ET method which was 48.00, 26.00, 15.00 and 14.33 individuals per $250 \mathrm{~g}$ soil for the same previous genera, respectively. 
Table 2. Efficiency of different methods for extracting nematodes from sandy soil (type 1) grown with banana cv. Balaika

\begin{tabular}{|c|c|c|c|}
\hline Nematode genera & $\begin{array}{c}\text { Extraction Trays } \\
\text { method } \\
\text { (ET method) }\end{array}$ & $\begin{array}{c}\text { Decanting + Sieving } \\
\text { method } \\
\text { (DS method) }\end{array}$ & $\begin{array}{c}\text { Centrifugal Flotation } \\
\text { method } \\
\text { (CF method) }\end{array}$ \\
\hline Meloidogyne & $268.33 \mathrm{~b}$ & $374.00 \mathrm{a}$ & $373.33 \mathrm{a}$ \\
\hline Helicotylenchus & $38.33 \mathrm{~b}$ & $48.33 \mathrm{a}$ & $53.00 \mathrm{a}$ \\
\hline Tylenchorhynchus & $40.00 \mathrm{~b}$ & $55.00 \mathrm{a}$ & $57.00 \mathrm{a}$ \\
\hline Criconemoides & $0.00 \mathrm{~b}$ & $22.00 \mathrm{a}$ & $23.66 \mathrm{a}$ \\
\hline Pratylenchus & $10.66 \mathrm{~b}$ & $15.33 \mathrm{a}$ & $14.66 \mathrm{a}$ \\
\hline
\end{tabular}

Means in each row followed by the same letter(s) are not significantly different at $\mathrm{P} \leq 0.05$ according to Duncan's multiple range test.

Table 3. Efficiency of different methods for extracting nematodes from sandy clay soil (type 2) grown with banana cv. Balaika

\begin{tabular}{|c|c|c|c|}
\hline Nematode genera & $\begin{array}{c}\text { Extraction Trays } \\
\text { method } \\
\text { (ET method) }\end{array}$ & $\begin{array}{c}\text { Decanting + Sieving } \\
\text { method } \\
\text { (DS method) }\end{array}$ & $\begin{array}{c}\text { Centrifugal } \\
\text { Flotation method } \\
\text { (CF method) }\end{array}$ \\
\cline { 2 - 4 } Meloidogyne & $375.00 \mathrm{~b}$ & $473.33 \mathrm{a}$ & $476.00 \mathrm{a}$ \\
\hline Helicotylenchus & $48.00 \mathrm{~b}$ & $148.66 \mathrm{ab}$ & $154.66 \mathrm{a}$ \\
\hline Tylenchorhynchus & $26.00 \mathrm{~b}$ & $93.66 \mathrm{a}$ & $98.00 \mathrm{a}$ \\
\hline Criconemoides & $15.00 \mathrm{ab}$ & $55.00 \mathrm{a}$ & $64.00 \mathrm{a}$ \\
\hline Pratylenchus & $14.33 \mathrm{~b}$ & $53.00 \mathrm{ab}$ & $66.00 \mathrm{a}$ \\
\hline
\end{tabular}

Means in each row followed by the same letter(s) are not significantly different at $\mathrm{P} \leq 0.05$ according to Duncan's multiple range test.

On the other hand, the effect of clayey soil (type 3) was observed in Table (4). The lowest number of the nematodes was extracted by the ET method which was 208.33, 24.00, 0.00, 0.00 and 7.33 individuals per $250 \mathrm{~g}$ soil for genera Meloidogyne, Helicotylenchus, Tylenchorhynchus, Criconemoides and Pratylenchus, respectively and in the same trend there are no significant differences between the DS and CF methods, with reference to the nematode numbers extracted by CF method. The Tylenchorhynchus was not extracted by the ET method may be due to the effect of the soil composition on the nematode motility. Moreover, Criconemoides was absent from all the tested methods. 
Table 4. Efficiency of different methods for extracting nematodes from clayey soil (type 3 ) grown with banana cv. Balaika

\begin{tabular}{|c|c|c|c|}
\hline Nematode genera & $\begin{array}{c}\text { Extraction Trays } \\
\text { method } \\
\text { (ET method) }\end{array}$ & $\begin{array}{c}\text { Decanting + Sieving } \\
\text { method } \\
\text { (DS method) }\end{array}$ & $\begin{array}{c}\text { Centrifugal } \\
\text { Flotation } \\
\text { method } \\
\text { (CF method) }\end{array}$ \\
\cline { 2 - 4 } & \multicolumn{2}{|c|}{ Nematode numbers / 250 g soil } \\
\hline Meloidogyne & $208.33 \mathrm{~b}$ & $376.66 \mathrm{a}$ & $373.60 \mathrm{a}$ \\
\hline Helicotylenchus & $24.00 \mathrm{~b}$ & $50.00 \mathrm{a}$ & $54.00 \mathrm{a}$ \\
\hline Tylenchorhynchus & $0.00 \mathrm{~b}$ & $54.33 \mathrm{a}$ & $0.00 \mathrm{a}$ \\
\hline Criconemoides & $0.00 \mathrm{a}$ & $0.00 \mathrm{a}$ & $15.00 \mathrm{a}$ \\
\hline Pratylenchus & $7.33 \mathrm{~b}$ & $13.33 \mathrm{a}$ & \\
\hline
\end{tabular}

Means in each row followed by the same letter(s) are not significantly different at $\mathrm{P} \leq 0.05$ according to Duncan's multiple range test.

Data in Table (5) showed the Relative Efficacy of the Extraction (REE\%) for each nematode genus in the three different soil types. In the sandy soil type, DS method was the most efficient in extracting the Meloidogyne and Pratylenchus which recorded 36.82 and $37.71 \%$. On the other hand, the CF method was the most efficient in extracting Helicotylenchus, Tylenchorhynchus and Criconemoides which were $37.95,37.50$ and 51.82\%, respectively In the same trend the DS method was the most effective one in the extracting Meloidogyne (39.29\%) from sandy clay soil while, the CF method had the priority in extracting the genera Helicotylenchus (42.19\%), Tylenchorhynchus (50.76\%) and Pratylenchus (42.06\%) in the above mentioned soil type. Finally, the CF method had the upper hand in extracting all nematode genera from clayey soil, recorded 35.94, 44.03, 45.03, 47.77 and $49.50 \%$ for the genera Meloidogyne, Helicotylenchus, Tylenchorhynchus, Criconemoides and Pratylenchus, respectively.

Many authors have studied the effectiveness of the nematodes extraction methods among of them Grisse (1969) who reported that the centrifugal method is rapid one and can be used in all soil types and the nematode extracted by this method had larger number than filter method especially in the slow mobile nematodes like criconematides and referred to some larger nematode species such as Xiphinema and Longidorus can partially be lost by filter method extraction. Spaull and Braithwalte (1979) showed that using of decanting plus sieving method was efficient for extraction genera i.e. Rotylenchulus, Xiphinema and Paratrichodorus from sandy soil samples while, the decanting plus sieving and centrifugal sugar flotation methods were more efficient in the clayey soil for the nematode genera Pratylenchus, Scutellonema, Helicotylenchus, Macropothonia and Discocriconemella.

Talwana (2004) mentioned that extracting tray method is the simplest method which is a modified for Baermann Funnel Technique, it is very cheap, take no time, 
very good for extracting large number nematodes from soil and plant materials, was not suitable for inactive nematodes like trichodorids, longidorids, and criconematids.

\begin{tabular}{|l|c|c|c|c|c|c|c|c|c|}
\hline \multirow{2}{*}{ Nematode genera } & \multicolumn{3}{|c|}{ Sandy soil } & \multicolumn{3}{c|}{ Sandy clay soil } & \multicolumn{3}{c|}{ Clayey soil } \\
\cline { 2 - 10 } & ET*1 & DS*2 & CF $^{* 3}$ & ET*1 & DS*2 & CF*3 & ET*1 & DS*2 & CF*3 \\
\hline Meloidogyne & 26.42 & 36.82 & 36.76 & 21.73 & 39.29 & 38.97 & 28.32 & 35.74 & 35.94 \\
\hline Helicotylenchus & 27.45 & 34.60 & 37.95 & 18.75 & 39.06 & 42.19 & 13.66 & 42.31 & 44.03 \\
\hline Tylenchorhynchus & 26.32 & 36.18 & 37.50 & 0.00 & 49.24 & 50.76 & 11.94 & 43.03 & 45.03 \\
\hline Criconemoides & 0.00 & 48.14 & 51.82 & 0.00 & 0.00 & 0.00 & 11.19 & 41.04 & 47.77 \\
\hline Pratylenchus & 26.22 & 37.71 & 36.06 & 20.55 & 37.38 & 42.06 & 10.75 & 39.75 & 49.50 \\
\hline
\end{tabular}

Table 5. Relative efficacy of nematode extraction (\%) using three methods in three different soil types.

$\mathrm{REE} \%=\frac{\text { No.of nematode individuals extracted by the met hod }}{\text { Total number of the nematodes extracted by the three met hods }} \times 100$

ET*1: Extracting Trays method

DS*2: Decanting + Sieving method

$\mathrm{CF}^{* 3}$ : Centrifugal flotation method

Hooper et al. (2005) suggested that some nematode extraction methods from the soil samples e.g. sieving technique and modified Baermann technique can lose the sluggish and nonactive nematodes and recommended flotation technique for being the most efficient and quickest extraction method for active and sedentary nematodes from soil.

Centrifugal flotation method (CF) had several advantages versus Cobb's method, the first one depended on specific gravity, sample size (about 50g), besides extraction efficiency was high, costs of equipment medium, labor cost medium and water consumption were low. On the other hand, the second method depended on nematode mobility, the rate of settling, size, and shape of sieves, the sample size (100g), extraction efficiency was high for active forms, cost of equipment and labour was low and water consumption was high (Van Bezooijen, 2006).

Sarah and Boisseau (2008) referred that centrifugal flotation method can extract all nematode species and all life stages from the root and soil particles. Moser and Frankenbach (2009) found that the Cobb's method was more efficient than ISO method (International Organization for Standardization, 2005) in extraction nematodes from the soil samples and it achieved about $90 \%$ higher than the other methods of extraction. Mahesh Kumar et al. (2012) indicated that the centrifugal method was the most efficient method for extracting all stages of plant-parasitic nematodes from the soil and plant materials when compared with other methods, and 
among of the genera extracted by this method were Meloidogyne, Pratylenchus, Rotylenchulus, and Tylenchorhynchus. Hossain et al. (2016) showed that using centrifugal flotation method for extracting nematodes from the soil and plant parts was relatively faster and the nematode suspension was clear. It was superior when compared with Cobb's method. The above findings agreed with those obtained in the present investigation.

It could be concluded that the centrifugal flotation method was the fastest method when compared with the other methods and can extract all the nematode genera from the tested samples and the final suspension was mainly clear. On the other hand, when the priority for the water management, the extracting trays method was superior, since a small amount of water is used and not expensive method. However, in the inoculum experiments, it could recommend extracting trays and decanting plus sieving methods.

\section{REFERENCES}

Anon, (2013). Nematode extraction. European and Mediterranean Plant Protection Organization, 43(3): 471-495.

Cobb, N.A. (1918). Estimating the nematodes population of the soil. Agric. Tech. Circ.Bur. Pl. Ind. U.S. Dep. Agric. No.1. 48 pp.

Gooris, J. and d'Herde, C.J. (1972). A method for the quantitative extraction of eggs and second stage juveniles of Meloidogyne spp. from the soil. State Agricultural Research Centre, Ghent, Belgium.

Grisse, A.T.De (1969). Comparison of the filter method and the sugar centrifugal flotation method for the extraction of parasitic nematodes from soil. Mededelingen van de Rijksfaculteit Landbouwwetenschappen te Gent. 34: 57-69. https://library.wur.nl/WebQuery/titel/2089647.

Hopper, D.J.; Hallmann, J. and Subbotin, S.A. (2005). Methods of extraction, processing, and detection of plant soil nematodes. Pp 53-84. In: Plant parasitic nematodes in subtropical and tropical agriculture. Luc M.; Sikora A.R. and Bridge J., 2 Eds. CAB International, Wallingford, UK.

Hossain, M.; Moens, M. and Sutter, Nancy D. (2016). Nematode feeding types in different soil habitats and a subsequent study in a maize field. J. Agri. Res. 4(5): 204-210.

Mahesh Kumar R.; Catherine, S. C., and Raveendra, H. R.(2012). Comparative efficiency in different methods of extracting nematode from soil and plant material. Int. J. Adv. Bio. Res. 2(1): 143-146.

McSorley, R. (1987). Extraction of nematodes and sampling methods. Pp. 13- 41. In: Principles and Practice of Nematode Control in Crops. Brown, R.H. and Kerry, B.R. Academic Press, Australia.

Moser, T. and Frankenbach, S. (2009). Methodological adaptation for nematodes extraction in forest soils of the southern Mata Atlântica. Pesq. agropec. bras. 44 (8): $275-280$.

MSTAT VERSION 4 (1987). A software program for the design and analysis of agronomic research experiments. Michigan, USA, Michigan State University.

Oostenbrink, M. (1960). Estimating nematode populations by some selected methods. Pp. 85-102. In: Nematology. Sasser J.N. and Jenkins W.R. Eds. The University of North Carolina Press, Chapel Hill, NC(US). 
S'Jacob, J.J. and Van Bezooijen, J. (1984). A manual for practical work in nematology. Wageningen: Wageningen Agricultural University. 76p.

Sarah, J.L. and Boisseau, M. (2008). Nematode extraction from banana roots by the centrifugal-flotation technique. Fruits. 63: 249-251.

Seinhorst, J.W. (1988). The estimation of densities of nematode populations in soil and plants. Vaxtskyddsrapporter, Jordbruk No. 51, 107pp.

Spaull, V.W., and Braithwaite, J.M.C. (1979). A comparison of methods for extracting nematodes from soil and roots of sugarcane. Proceeding of the South African Sugar Technologists' Association. Pp103-107.

Talwana, H. (2004). Techniques for nematode diagnosis and handling. Pp2-19. In: Nematology Training Manual. Kimenju, J.; Sibanda, Z.; Talwana, H. and Wanjohi, W. Eds, Nematology Initiative for Eastern and Southern Africa.

Van Bezooijen, J. (2006). Methods and techniques for nematology. Pp.118. www.nem.wur.nl/NR/.

Whitehead, A.G. and Hemming, J. R. (1965). A comparison of some quantitative methods of extracting small vermiform nematodes from soil. Annals Appli. Biol., 5 (1): 25-38.

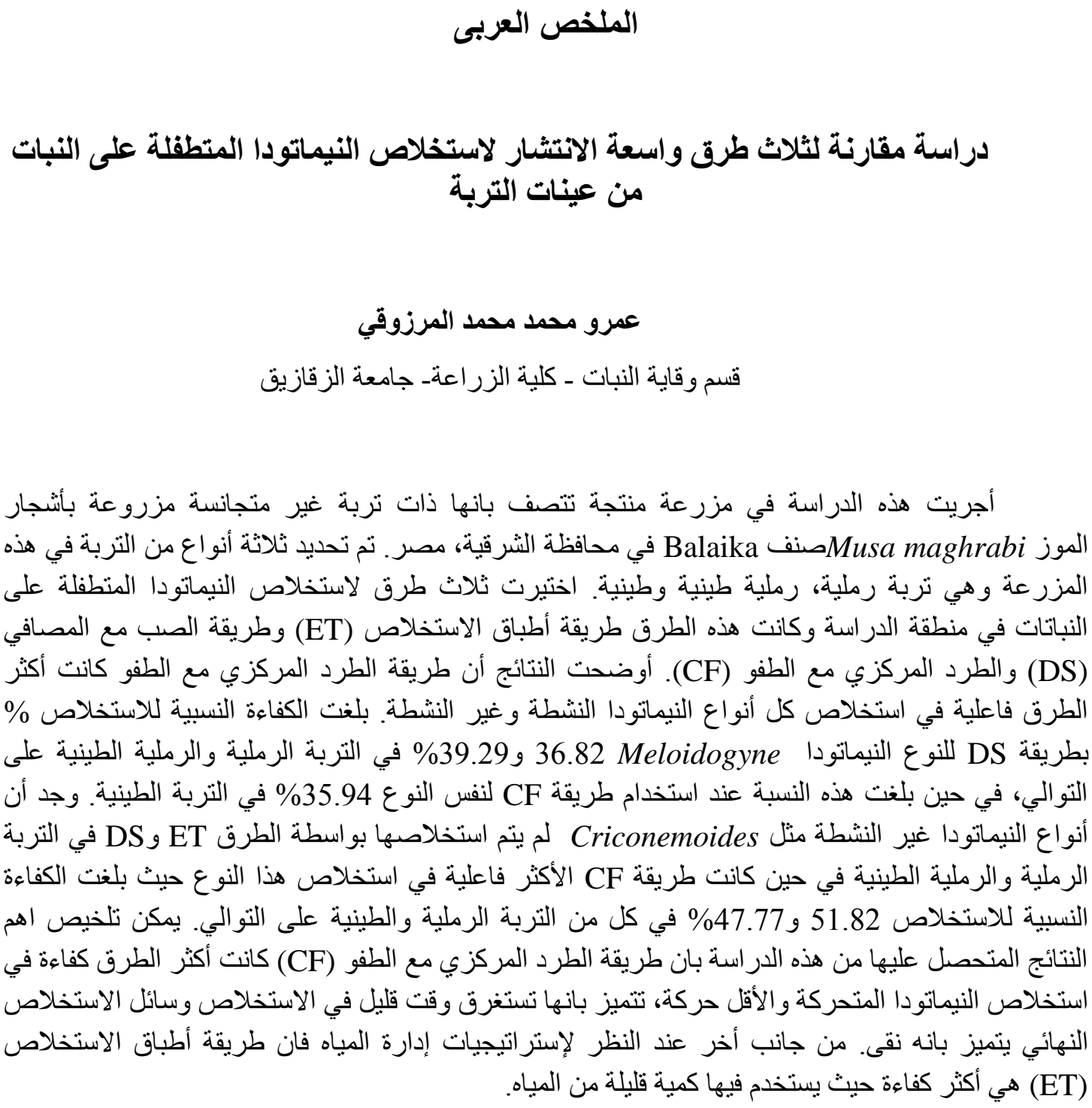

